\title{
Market power and bargaining power in the EU food supply chain: the role of Producer Organizations ${ }^{1}$
}

\author{
Alessandro Sorrentino*, Carlo Russo**, Luca Cacchiarelli*
}

DOI: $10.30682 / \mathrm{nm} 1804 \mathrm{~b}$

Jel codes: D43, L11, L44, Q11

\begin{abstract}
Imperfect competition in the food supply chain is a concern for several "weak agents" such as small farmers and consumers. Given the difficulties in applying standard anti-trust regulations in the agrifood system, a growing interest is emerging in a decentralized approach where private entities, such as Producer Organizations (PO), are given active role in the governance of the agricultural markets. We present a simple bargaining model assessing the POs'capacity to rebalance bargaining power along the supply chain.

The results show that POs can benefit farmers by strengthening their negotiation power, improving their bargaining position and worsening the buyer's one. Imposing a minimum size for POs may improve their effectiveness in affecting the buyer's bargaining position. Such requirement should be calibrated on the structure of the downstream (upstream) relevant market.
\end{abstract}

Keywords: Producer Organization, Bargaining power, Market power, Food supply chain, CAP.

\section{Introduction}

Balancing power across the agro-food supply chain is a key concern in modern agricultural policy. Welfare and distributional concerns arise at any stage of the food supply chain when "weak agents" such as small farmers and consumers negotiate with "strong agents" operating in more concentrated (industrial and retailing) sectors. The topic is especially controversial because of the continuing erosion of the agricultural share of the total value added in the food system ${ }^{2}$.

Value redistribution is a major policy concern, as the public opinion and policy-makers perceive that the farmers' share of food value is "unfairly low" (e.g. Busch and Spiller, 2016). Standard anti-trust regulation is often difficult to apply in this regard, due to the unique features of the agri-food supply chains (e.g., Bolotova, 2014, about consequences for farmers of competition law). Consequently, collective action is

\footnotetext{
${ }_{1}$ The paper is based on the results in a report commissioned to the Authors by the European Parliament - COMAGRI Sorrentino et al., 2016).

2 In 2011 the agricultural share of value added was $21 \%$, compared to $28 \%$ of food industry and $51 \%$ of food retail. In 1995 , the shares were $31 \%, 31 \%$ and $38 \%$, respectively (EP, 2015).

* Dipartimento di Economia e Impresa, Università della Tuscia, Viterbo, Italy.

** Dipartimento di Economia e Giurisprudenza, Università di Cassino e del Lazio meridionale, Italy.

Corresponding author: cacchiarelli@unitus.it.
} 
often regarded as a viable solution for mitigating possible bargaining power problems in the entire Mediterranean area (e.g., Bouamra Mechemache and Zago, 2015; Ben and Soussi, 2015; Haddad et al., 2017) ${ }^{3}$. The implicit assumption is that aggregation of farmers in such an organisation and coordination can improve both market efficiency and the farmers' bargaining power.

In the EU, the Common Agricultural Policy (CAP) defines a general framework for collective action in agriculture. Producer Organisations (PO), Association Producer Organisations (APO) and Inter-Branch Organisations (IBO) are institutions that are designed to favour farmer aggregation and redistribution of value. The 2013 CAP reform increased the public support to these institutions even further. The analysis focuses on the bargaining implications of POs. The goal is to contribute to the public debate about the rebalancing of power in the food system. To this purpose, a simple bargaining model is used to illustrate the theoretical impact of horizontal aggregation on the distribution of bargaining power and value across the agro-food supply chain. The model supports the conclusion that POs can be an effective tool to rebalance bargaining power, yet their efficiency depends on several contingent factors such as scale and the ability of finding marketing alternatives. Although the model focuses on POs, the conclusions can be easily generalized to other forms of collective action.

\section{Background}

In this section an overview of two key topics in PO studies is provided: POs' performance evaluation and the definition of various types of power. The choice of these two topics is instrumental to the presentation of the model in Section 3. The aim is to motivate the choice of a bargaining model to describe the impact of POs on the agri-food chains.

\subsection{The performance and efficiency of POs}

The assessment of POs' impact is an open question and there is not consensus in empirical studies (Van Herck, 2014). The conflicting empirical findings are the consequence of the relevance of the specific institutional context and of the heterogeneity in the measurement criteria used for the evaluation.

The multi-dimensionality of vertical interactions along the supply chain is a key characteristic of today's food system. For instance, in a standard supply contract with supermarkets, parties agree on prices, quality, production standards, logistics, timing of delivery and payments, promotions, trade spending, risk allocation and many other issues. The complexity of the outcomes makes evaluation of the PO performance difficult. Several works have investigated on the efficiencies generated by POs in terms of increasing productivity, rising of farmers' welfare and ensuring reasonable consumer prices (e.g. Van Herck, 2014; Heyder et al., 2011). Empirical studies found mainly two types of PO's effects on outcome: (I) a private effect, which is the ability of the PO to pay members higher prices than the market (e.g.: Cazzuffi, 2012) and (II) an industry-level effect (also known as competitive yardstick effect), which is the ability of POs to determine higher prices for all farmers when their market share is large (e.g.: Bijman et al., 2012). Moreover, some evidences, as found by Arcas et al. (2008) in Spanish F\&V sector, concern a positive correlation between the size of the PO and its performance because of cost reduction through economies of scale and differentiation through innovation. However, other studies find no significant relation between size of PO and efficiency and/or profitability (Sueyoshi et al., 1998). Therefore, although most of the evidence suggests that significant economies of scale exist, larger POs sometimes could also be associated with structural complexity and reduced flexibility, which may lead

\footnotetext{
${ }^{3}$ It should be noted that, according to the main characteristics of the actors involved at different stages of the food supply chain, the increasingly use of complex forms of coordination, integration and contracts leads to different kind of food supply chains. Their shape depends on the role of the various stakeholders, the kind of relationship established by the actors, the scope for coordination and the model of governance assuring the overall working of the chain (Carbone, 2017).
} 
to decrease efficiency (Van Herck, 2014). Furthermore, the internationalization of the activities of the PO might improve their performance, especially in smaller countries where POs face smaller domestic market. Finally, there are not works on how the presence of POs stabilise markets and assure the availability of supplies. Overall, although several studies report cases of positive impact of POs on farm prices, the empirical evidence can hardly be generalized and the effectiveness of POs is still an open question.

The model focuses on the private effect of POs, measuring the benefit as the possible increase in the farmer's share of the total value of trade. The choice is consistent with the current institutional setting and with the literature. In particular, POs are private associations. Therefore it is assumed that the action of the PO is driven by selfish rationality. Members want to maximize own benefits with no consideration of possible social impact.

\subsection{From market power to bargaining power}

Power, i.e. the ability of strong agents to direct or influence the behaviour of others, is a major concern in agricultural policy. The presence of leading firms who are able to coordinate the entire value chains is a distinctive characteristic of many governance forms of modern agricultural markets (e.g., Carbone, 2017). In principle, strong leading-firms might use their power to extract profits and value from the weaker coordinated ones. Due to subsidy decoupling and, more in general, the CAP reforms in the late twenty years farmers are nowadays more vulnerable to this threat than they used to few decades ago (e.g., Russo et al., 2011).

The problem is well known in the literature and it originated a large number of contributions (e.g., McCorriston, 2002). The definition of power is a key issue in these studies. The literature identifies several kinds of powers and the choice of the most fitting definition is a critical modelling choice and has strong policy and welfare implications (e.g., OECD, 2008). Among the different definitions of power, the literature mainly focuses on market power and bargaining power.
Market power is defined as «The ability of a firm (or group of firms) to raise and maintain price above the level that would prevail under competition is referred to as market or monopoly power». (Khemani and Shapiro, 1993, p. 57, similar definition in Perloff et al., 2007). The definition can be easily extended to include monopsony/oligopsony power, i.e., the ability to lower and maintain purchasing price below the perfect competition level.

Market power theory is based on two key assumptions: (I) the firm(s)' actions influence the market equilibrium; (II) firm(s) are aware of this influence and take it into account in their planning (optimization problem). A general conclusion deriving from this theory is that market power results in reduced trade and - holding everything else constant - loss of social welfare (e.g., Dockner, 1993; Sexton and Zhang, 2001). This is the fundamental justification of policies aimed at safeguarding an acceptable degree of competition in the markets.

Bargaining power can be defined as «the power to obtain a concession from another party by threatening to impose a cost, or withdraw a benefit, if the party does not grant the concession». (Kirkwood, 2005). Unlike market power theory, the emphasis of the definition is on a specific negotiation among certain parties, whilst industry-level studies are less common than in market power theory.

In principle, both bargaining power and market power may result in lower prices or surplus transfers. The main difference is that market power achieves this result through the act of purchasing/supplying less, whereas bargaining power uses the threat of withdrawing from the transaction. The key difference is that the exertion of market power always determines lower trade level compared to perfect competition, while this conclusion is not necessarily true in the case of bargaining power.

In the present work bargaining power is considered a more appropriate definition for the case of interest than market power. Bargaining models are more effective in describing the complexity of the food system compared to market power models, whose predictive power is increasingly questioned (e.g., Sexton, 2013). 
Market power models predict scarcity, while bargaining models are consistent with retailers' "big-box" strategies. Market power theory focuses on prices and quantities. Bargaining power models can accommodate complex contracts which include many other dimensions such as payment delay, quality, integrated logistics, risk allocation, promotions, trade spending. Also, market power models are non-cooperative, while the bargaining framework can model cooperation agreements and coordination.

For these reasons, the present analysis focuses on bargaining power. The choice is consistent with the explicit mention in the $\mathrm{CMO}$ regulation of strengthening farmers' bargaining power as one of PO objectives (Reg. 1308/2013). Furthermore, as long as POs' actions, such as joint supply and production planning, are aimed at strengthening farmers' bargaining power without affecting the whole trade, competition rules concerning producers agreements are not binding anymore.

\section{Bargaining power and the relationships along food supply chain}

The purpose of this section is to develop the simplest possible bargaining model able of illustrating the basic functioning of POs. A bilateral model based on the typical Nash bargaining model has been used (Nash, 1950).

Consider a buyer and a seller negotiating about a trade opportunity. A food processor or retailer acts as middleman between the farmer and the consumers. He buys a product $\mathrm{X}$ from the farmer and sells it to the consumer. The negotiation is successful if buyer and seller agree on the quantity supplied, the wholesale price and all other contract terms (lump-sum transfers such as trade spending, etc.). If the negotiation is successful a contract is written, trade happens and parties share the total gain from trade (TGT) according to the rules agreed in the contract. If the negotiation fails, trade does not happen and parties gain the profits from the next best available alternatives (the so-called disagreement payoffs or outside option profits). For simplicity, it is assumed that the parties first agree on the quantity that maximizes TGT and then bargain over its distribution using lump-sum transfers. In our simplified model the middleman receives the sale revenues paid by consumers and then uses the lump-sum transfer to share the economic benefit with the farmer.

Figure 1 summarizes the key elements of a simple bilateral bargaining. The TGT can be decomposed into three areas. The farmer's disagreement payoff is the surplus that the farmer would receive from the next best alternative if the transaction fails (the dark grey area in Figure 1). If the middleman offers a share of TGT that is smaller than the disagreement payoff, the farmer can credibly threat to withdraw from the trade. The middleman's disagreement payoff is his/her surplus from the next best outside option (the light grey area in Figure 1). The middleman can credibly threat to fail any negotiation resulting in a lower share of TGT than the disagreement payoff. The difference between the TGT and the aggregate disagreement payoff (if positive) is the negotiation space (dotted area in Figure 1). The boundaries between the disagreement payoff areas and the negotiation space are the agents' bargaining positions.

Any point in the negotiation space is a feasible negotiation outcome because no agent can credibly threat the other to fail the trade. The specific outcome within the negotiation space depends on the relative magnitude of negotiation power. Negotiation power is defined as the ability to impose a negotiation outcome that is as close as possible to the most desired point in the negotiation space. It depends on the ability of imposing negotiation rules, negotiation skills, patience, technical constraints, risk attitudes and information $^{4}$. If the middleman has a strong negotiation power compared to the farmer, then the outcome transfer is closer to the farmer's bargaining position than to the middleman's one. Vice versa, if the middleman is relatively weak, the outcome is close to his/her position.

\footnotetext{
4 In the literature, negotiation power is often referred to as "bargaining power" (e.g., Dukes et al., 2006). In this paper, a different term is used in order to avoid ambiguities with the Regulator's use of the wording "bargaining power". In the regulation, the term "bargaining power" refers to the joint effect of bargaining position and negotiation power.
} 
Figure 1 - Bilateral, zero-sum bargaining.

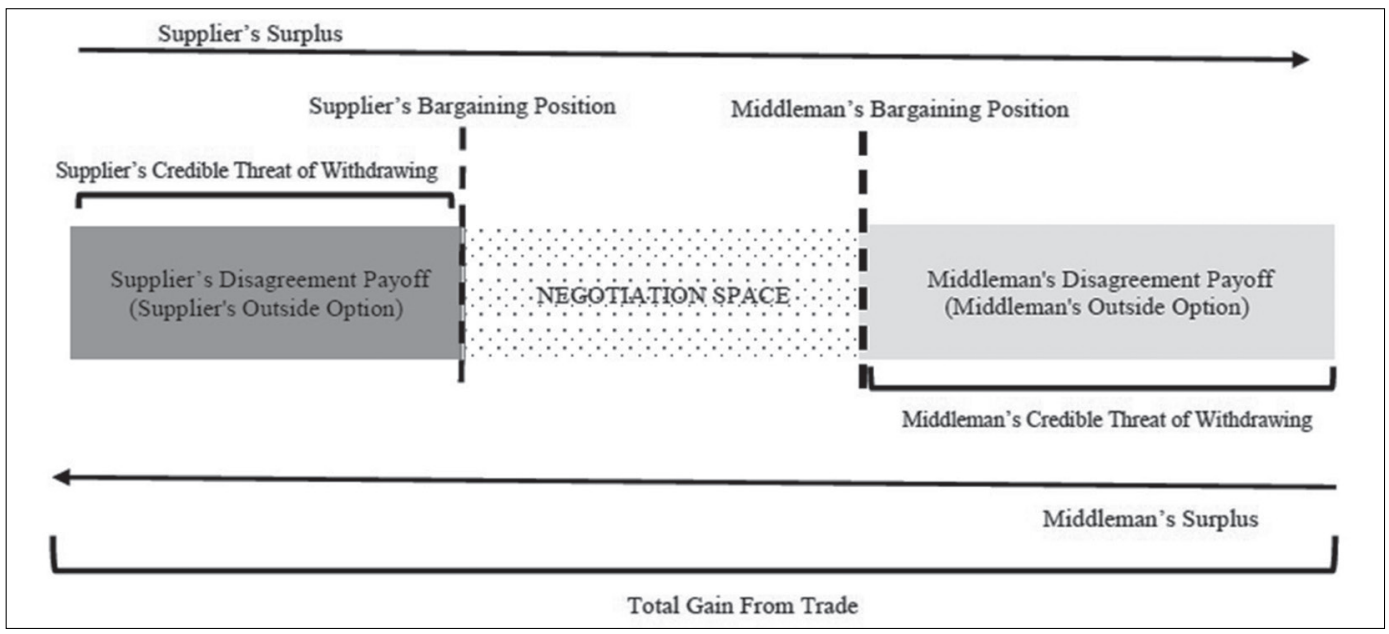

\section{PO and the balancing of bargaining power}

In this section the bilateral framework is extended to discuss the PO impact on farmers' negotiation power and bargaining position.

\subsection{PO and negotiation power}

In theory, horizontal integration and joint selling can result in stronger bargaining, or at least in an improved ability to resist to counterparts' negotiation power. Organized farmers might have access to resources that are difficult to be achieved by individual producers such as: services, capital or information to support the negotiation activities. Procurement of legal services in litigations about unfair trade practices, hiring of trained negotiators, improving inventory management and buyer selection are examples of PO services that may have an impact on negotiation power.

Despite these opportunities, in practice, the actual ability of POs to reallocate negotiation power along the agro-food supply chain is an open question (Van Herck, 2014).

\subsection{PO and bargaining position}

A bargaining model has been used to explain the basic link between horizontal integration and bargaining position. Consider a simple model of sequential bargaining between a middleman and many farmers. The middleman picks a random farmer and starts a bilateral negotiation. If the negotiation fails, the middleman moves on and negotiates with another supplier. This model can be used to describe the horizontal integration process. Joint selling is represented as a reduction in the number of farmers in the market. Figure 2 illustrates the impact of a change in farmers' number on bargaining positions and negotiation outcome (based on Inderst and Wey, 2007) ${ }^{5}$. In this example, a middleman and a farmer bargain over the total gain from a trade (TGT). In order to focus on the effects on bargaining position it is assumed that the two parties have the same

\footnotetext{
${ }^{5}$ Such a representation is a simplification of Inderst and Wey (2007) model. In their paper, they model the interaction between a group of suppliers and buyers as a set of bilateral negotiations. The $N$ buyers transform one unit of input in one unit of output at no cost and sell the output to $N$ independent markets. Each player (either buyer or supplier) is free to negotiate with other firms, if the agreement with the counterpart is not achieved (sequential bilateral negotiation model). Given the model assumptions, the firms agree on an efficient quantity and bargain over a transfer (pp. 650-651). This paper uses a similar setting with two main simplifications: suppliers adopt a constant marginal cost technology and quantities are exogenous. Also, in figure 2 it is assumed that the supplier's disagreement payoff is exogenous (the assumption is released in figure 3 ).
} 
Figure 2 - Bargaining positions and negotiation outcome as a function of farmers' number.

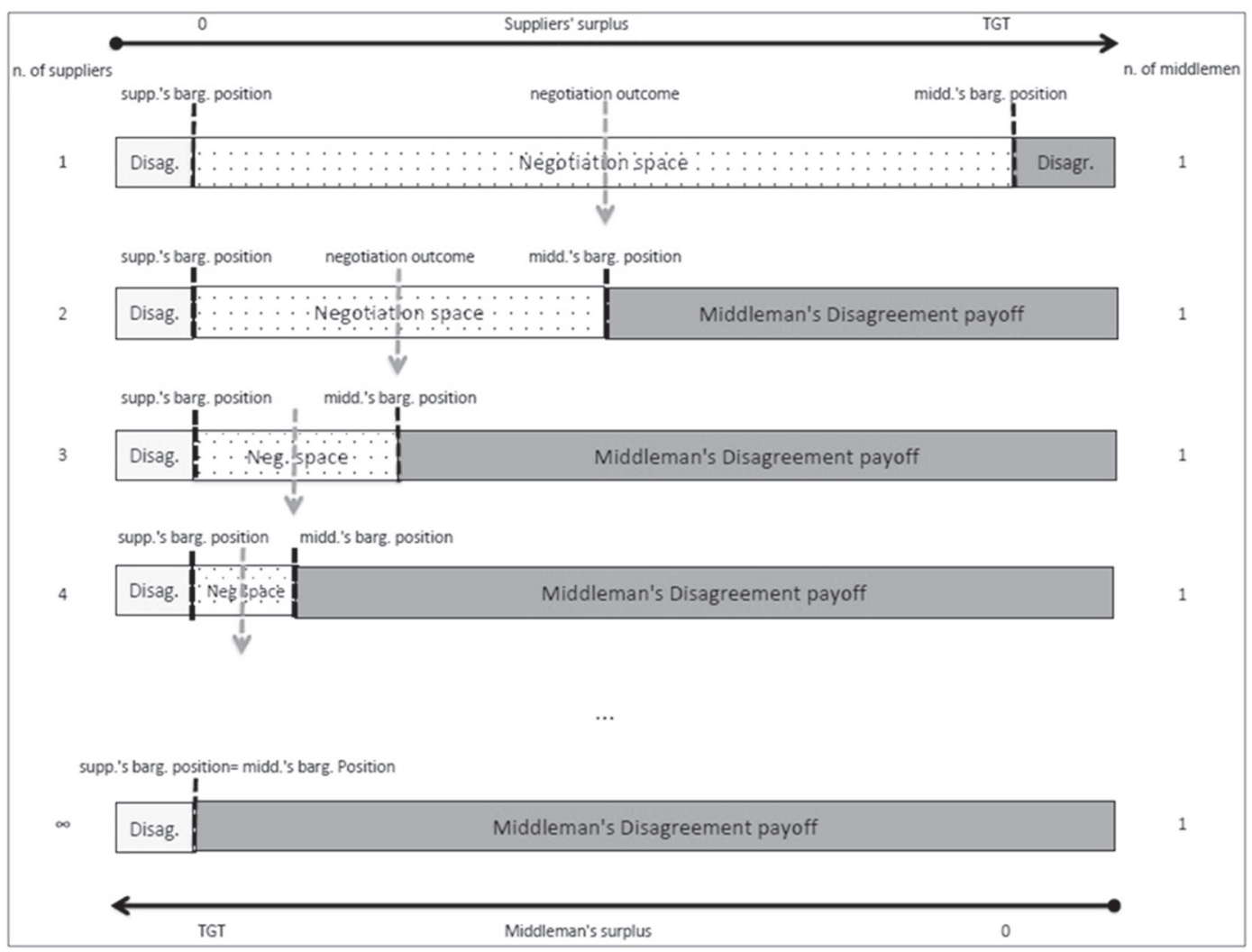

relative bargaining power so that they divide the negotiation space in equal shares.

If there are only one farmer and one middleman (first row of Figure 2), the bargaining positions are at the extremes of the segment (the dotted black marks): if negotiation fails, both firms achieve minimum payoffs. Otherwise, negotiation continues and the parties divide the negotiation space based on their negotiation power. The negotiation outcome is at midpoint of negotiation space, due to the assumption of equal negotiation power, and - in this case only - the firms split it in two equal shares.

Now assume that the middleman can engage in a sequential bargaining with two identical farmers (second row in Figure 2). The middleman buys from one farmer only, but now has two possible negotiation partners. The middleman randomly chooses one supplier and starts negotiations. The presence of a second farmer changes the middleman's bargaining position, because if the negotiation fails he/she can still buy from the other farmer in a bilateral bargain. This implies that the middleman's bargaining position is stronger and the negotiation space is smaller. In other words, the opportunity to trade with another farmer moves the negotiation space in favour of the middleman and to detriment of the farmers that will receive a smaller share compared to the previous case (only one supplier). The larger the number of potential farmers, the stronger is the buyer's bargaining position and the more favourable is the negotiation outcome for the buyer to detriment of farmers (as it is illustrated in the third and following rows of Figure 2). With an infinite number of farmers, the middleman appropriates of the entire negotiation space, regardless of the intensity of the relative negotiation power.

A PO can reduce the number of the middleman's negotiation counterparts in the market. Farmers join the PO and bargain with the mid- 
dleman collectively. This effect is represented in Figure 2 moving along the rows bottom-up. As the number of farmers decreases, the middleman disagreement payoff decreases and the farmer can appropriate of a larger value.

Formally, the result can be proven by recursive backward induction. If there are only one farmer and one middleman bargaining over the distribution of the $T G T$, the farmer's payoff $\pi_{1,1}^{F}$ is:

$$
\pi_{1,1}^{F}=D P S 11+\lambda(T G T-D P M 11-D P S 11)
$$

where DPM11 is the middleman's exogenous disagreement payoff in the case there is only one middleman and only one supplier, DPS11 is the farmer's disagreement payoff and $\lambda \in(0,1)$ is a parameter representing the farmer's relative negotiation power, with $\lambda=0$ if the middleman holds maximum power and $\lambda=1$ if the farmer holds maximum power. In this setting, $\lambda$ represents the share of the negotiation space that the farmer can appropriate (e.g., Muthoo 1999).

Similarly, the middleman's payoff $\pi_{1,1}^{M}$ is:

$\pi_{1,1}^{M}=D P M 11+(1-\lambda)(T G T-D P M 11-D P S 11)$.

If a second, identical farmer enters the market, $\pi_{1,1}^{M}$ becomes the middleman's disagreement payoff in the transaction. If the transaction with the selected farmer fails, the middleman can still obtain $\pi_{1,1}^{M}$ from the other farmer. Consequently, the farmer's and the middleman's disagreements payoff $\left(\pi_{2,1}^{F}\right.$ and $\pi_{2,1}^{M}$, respectively) are

$$
\pi_{2,1}^{F}=D P S 11+\lambda\left(T G T-\pi_{1,1}^{M}-D P S 11\right)
$$

and

$$
\pi_{2,1}^{M}=\pi_{1,1}^{M}+(1-\lambda)\left(T G T-\pi_{1,1}^{M}-D P S 11\right) .
$$

Generalizing the recursive relationship, $\pi_{n, 1}^{F}$ the farmer's payoff when $n-1$ other suppliers are in the market is computed as:

$$
\pi_{n, 1}^{F}=D P S 11+\lambda^{n} \cdot N S 11,
$$

and the corresponding middleman's payoff $\pi_{n, 1}^{F}$ :

$$
\pi_{n, 1}^{M}=D P M 11+\left(1-\lambda^{n}\right) \cdot N S 11,
$$

where $N S 11=T G T-D P M 11-D P S 11$ is the negotiation space when only one farmer and one middleman are in the market. As expected, $\lim _{n \rightarrow \infty} \pi_{n, 1}^{F}=D P S 11$ and $\lim _{n \rightarrow \infty} \pi_{n, 1}^{M}=D P M 11+N S 11$, meaning that when the number of farmers goes to infinity, the middleman captures the entire negotiation space, regardless of the value of $\lambda$. In general, $\pi_{n, 1}^{F}$ is strictly decreasing in $n$ and $\pi_{n, 1}^{M}$ is strictly increasing in $n$.

The same recursive approach can be applied to model an increasing number of identical middlemen. In this case, the larger the number of potential middlemen, the stronger is the farmer's bargaining position and the more favourable is the negotiation outcome for the farmer to detriment of buyers. A PO has several opportunities to increase the number of potential middlemen. Such opportunities usually are not affordable to individual producers because of production capacity constraints. POs may achieve a critical size that allows increasing the market channels spatially (e.g., foreign markets) as well as differentiating the products. In such a way a PO can increase its disagreement payoff and strengthen its bargaining position.

Figure 3 summarizes the findings of our model. The plot has been derived applying a recursive algorithm. The outcome of the transaction with $n$-1 farmers in the market is used as the middleman's bargaining position for the case of $n$ farmers. Similarly, the outcome of the transaction with $m-1$ middlemen in the market is used as the farmer's bargaining position for the case of $m$ middlemen. The graph reports the supplier's share of TGT as a function of the number of suppliers and middlemen in the market under the assumption of equally distributed negotiation power. The two solid lines DPS11 and DPM11 represent the value of the supplier's and the buyer's disagreement payoffs in a bilateral (one on one) negotiation, respectively. The dashed lines indicate the supplier's share given $n$ the number of supplier in the market. According to the model, the supplier's share decreases as the number of the $n-1$ alternative suppliers increases. The simulation shows that, if the buyer industry is highly consolidated, a relatively low number of suppliers is sufficient to allow the buyer to appropriate of almost all the negotiation space, 
Figure 3 - Supplier's share of TGT as a function of number of suppliers and number of middlemen.

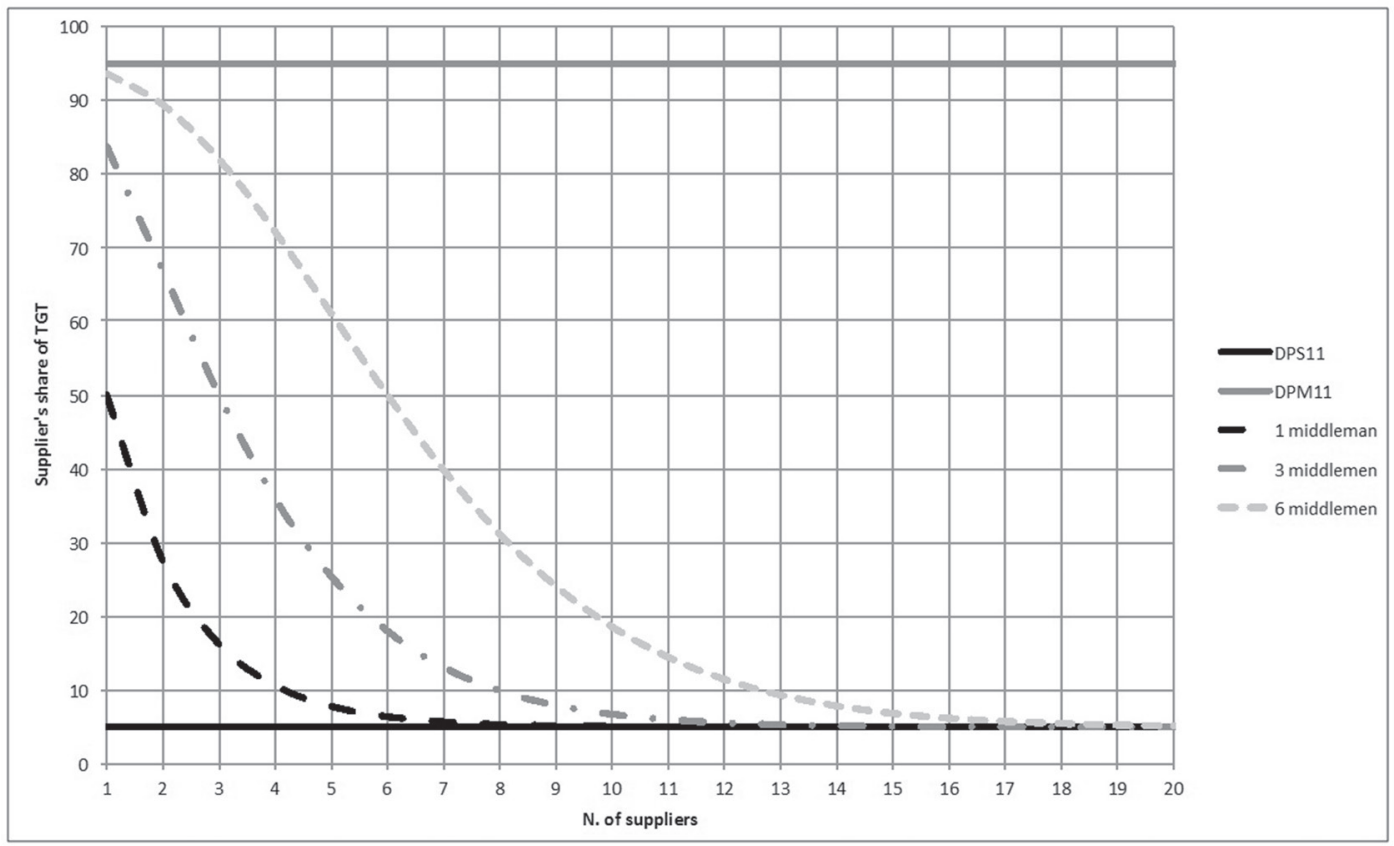

(Simulation based on the following assumptions: TGT=100, Supplier's disagreement payoff in a bilateral negotiation DPS11 =5, Middleman's disagreement payoff in a bilateral negotiation DPM11 =5, equal distribution of negotiation power).

regardless the intensity of the relative bargaining power. In the simulation, a monopsonistic buyer can take almost the entire negotiation space as the number of potential supplier exceeds the value of nine. In the case of six buyers, an almost complete appropriation is possible when at least 20 suppliers are in the market. In modern agricultural markets, the degree of concentration of farmers is very low compared with the buyers' one. The model suggests that POs can have a non-negligible impact only if they are able to achieve a sizable critical mass. Of course, the numerical simulation in Figure 3 cannot be used to predict the optimal minimum size of POs. Yet, the simulation suggests that small, local POs are expected to have little consequence on the bargaining outcome.

The theoretical model identified the basic economic mechanisms allowing POs to rebalance bargaining power along the food supply chain. Figure 4 illustrates the findings. Assume that farmers are bargaining with a buyer over the val- ue of a trade. The PO can improve farmers' final outcome in three ways: I) improving farmers' negotiation power (section 4.1), II) worsening the middleman's bargaining position, and III) improving farmers' bargaining position.

PO's horizontal integration can reduce buyer's trade options, worsening its bargaining position. The reduction of the buyer's disagreement payoff - holding everything else constant - increases the negotiation space, giving farmers the opportunity of appropriating of more value, holding the negotiation power constant. The simulation in Figure 3 suggests that in order to achieve a sensible increase in the farmers' share of value, the PO must be able to induce a significant degree of concentration in supply.

Associated farmers may have access to alternative marketing channels that are unavailable to individual firms, improving their disagreement payoff and their bargaining position. This implies that a PO can increase farmers' disagreement payoff. If this is the case, the negotiation 
Figure 4 - Rebalancing bargaining power: the role of PO.

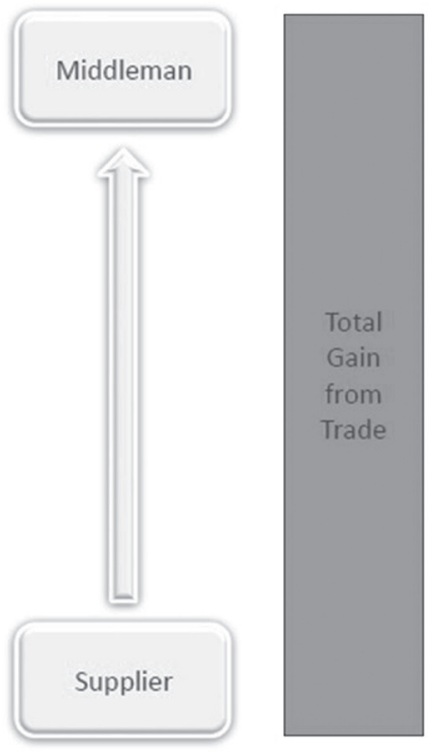

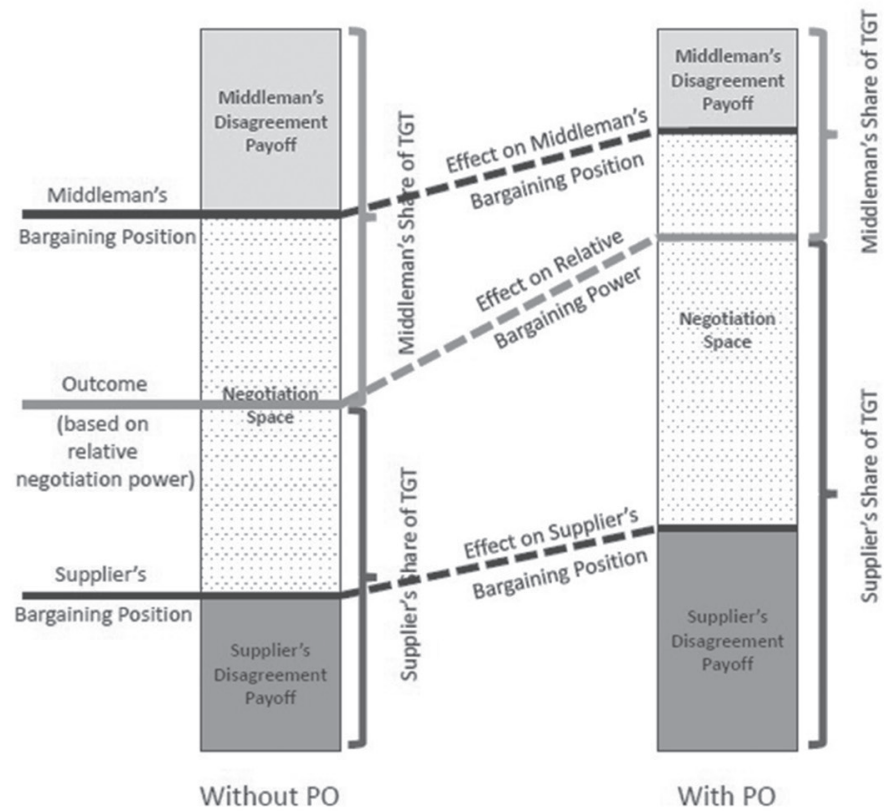

space is reduced to the buyer's detriment and farmers can keep a higher share of the TGT.

The theoretical model suggests that PO can benefit farmers in several ways. Even if countering large buyers' negotiation power might be difficult given the current structure of the agrifood supply chain, PO can still act to improve members' bargaining position by building alternative marketing channels. Noticeably, this strategy is fully compatible with competition regulation.

However, it is important to highlight that small POs might be unable to improve farmers' bargaining power and significantly alter the negotiation outcome. Likewise, the effectiveness of a PO in improving farmers' bargaining power also depends on the concentration of the downstream market. The more the downstream sector is consolidated, the larger the size of the PO must be in order to have a significant impact.

\section{Conclusion}

Welfare implications of competition at any stage of the food supply chain concern several 'weak agents' such as small farmers and con- sumers, and for that reason are of specific interests for policy-makers in the regulation of agricultural markets. The centralized top-down approach characterizing the CAP first pillar in the late 20th century has become obsolete and incapable of effectively governing a complex and rapidly evolving agro-food system. The recent 2013 reform opted for a more decentralized approach, and now private entities such as PO are assuming an increasing role in the governance of the agricultural markets.

Our model results show that PO can benefit farmers by strengthening their negotiation power, improving their bargaining position and worsening the buyer's one. The model suggests that imposing a minimum size for POs may improve their effectiveness in affecting the buyer's bargaining position. Such requirement should be calibrated on the structure of the downstream (upstream) relevant market: more consolidated buying industries call for larger POs. Furthermore, promoting the diversification of the POs' market channels is a key success factor, as these action can improve the PO's bargaining position. This objective can be pursued even allowing multi-sector POs. Noticeably, large, multi-sector 
POs may involve a heterogeneous membership. Managerial issues in collective action may rise from such circumstance (e.g., Dentoni et al., 2012 regarding GI consortia, or Chaddad and Iliopolous, 2013, about cooperatives).

Although our analysis focuses on the EU POs, the results can be easily generalized to other forms of collective action in agriculture, such as cooperatives. In modern agricultural markets, transactions are increasingly organized in the form of direct bargaining and contracting. In this context, farmer aggregation - in its various forms - can attenuate the imbalances in bargaining power along the agri-food supply chains.

\section{Reference}

Arcas N., Garcia D., Guzman I., 2011. Effect of size on performance of Spanish agricultural cooperatives. Outlook on Agriculture, 40(3): 201-206.

Ben S. and Soussi M., 2015. Contractualization and performance of agribusiness: the case of the dairy activity in Tunisia. African Journal of Agricultural and Resource Economics, 10(3): 250-264.

Bijman J., Iliopoulos C., Poppe K.J., Gijselinckx C., Hagedorn K., Hanish M., van der Sangen G., 2012. Support for Farmers' Co-operatives. Final report.

Bolotova Y., 2014. Agricultural supply management and antitrust in the United States system of agribusiness. International Food and Agribusiness Management Review, 17(3): 53.

Bouamra-Mechemache Z., and Zago A., 2015. Introduction: Collective action in agriculture. European Review of Agricultural Economics, 42(5): 707-711.

Busch G., and Spiller A., 2016. Farmer share and fair distribution in food chains from a consumer's perspective. Journal of Economic Psychology, 55: 149-158.

Carbone A., 2017. Food supply chains: coordination governance and other shaping forces. Agricultural and Food Economics, 5(1), 3.

Cazzuffi C., 2012. Small scale farmers in the market and the role of processing and marketing cooperatives: A case study of Italian dairy farmers. Thesis submitted for the degree of Doctor of Philosophy, Department of Economics, University of Sussex.

Chaddad F. and Iliopoulos C., 2013. Control rights, governance, and the costs of ownership in agricultural cooperatives. Agribusiness, 29(1): 3-22.
Dentoni D., Menozzi D. and Capelli M.G., 2012. Group heterogeneity and cooperation on the geographical indication regulation: The case of the "Prosciutto di Parma" Consortium. Food Policy, 37(3): 207-216.

Dockner E.J., 1992. A dynamic theory of conjectural variations. The Journal of Industrial Economics, 377-395.

Dukes A., Gal-Or E. and Srinivasan K., 2006. Channel bargaining with retailer asymmetry. Journal of Marketing Research, 18: 84-97.

European Commission, 2015. You are part of the food chain. Key facts and figures on the food supply chain in the European Union. EU Agricultural Markets Briefs, n. 4, June 2015.

European Parliament, 2015 - Policy Department B based on data from European Commission, 2015. Parliamentary Questions, Question for written answer to the Commission on the Food Supply Chain, E-000251/15.

Haddad N.O., Ton G., Sraïri M.T. and Bijman J., 2017. Organisational Challenges of Moroccan Dairy Cooperatives and the Institutional Environment. International Journal on Food System Dynamics, 8(3): 236-249.

Heyder M., Makus C., Theuvsen L., 2011. Internationalization and Firm Performance in Agribusiness: Empirical Evidence from European Cooperatives. International Journal on Food System Dynamics, 2(1): 77-93.

Inderst R., Wey C., 2007. Buyer power and supplier incentives. European Economic Review, 51(3): 647-667.

Khemani R.S., Shapiro D.M., 1993. An empirical analysis of Canadian merger policy. The Journal of Industrial Economics: 161-177.

Kirkwood J.B., 2005. Buyer Power and Exclusionary Conduct: Should Brooke Group Set the Standards for Buyer-Induced Price Discrimination and Predatory Bidding? Antitrust Law Journal, 72, 625.

McCorriston S., 2002. Why should imperfect competition matter to agricultural economists? European Review of Agricultural Economics, 29(3): 349-371.

Nash J., 1950. The bargaining problem, Econometrica, 18(2, Apr. 1950): 155-162.

OECD, 2008. Monopsony and buyer power, OECD roundtables available at https://www.oecd.org/daf/ competition/44445750.pdf.

Perloff J.M., Karp L.S., Golan A., 2007. Estimating market power and strategies. Cambridge: Cambridge University Press.

Russo C., Goodhue R.E., Sexton R.J., 2011. Agricultural Support Policies in Imperfectly Competitive 
Markets: Why Market Power Matters in Policy Design. American Journal of Agricultural Economics, 93(5): 1328-1340.

Sexton R.J., 2013. Market power, misconceptions, and modern agricultural markets. American Journal of Agricultural Economics, 95(2): 209-219.

Sexton R.J., Zhang M., 2001. An assessment of the impact of food industry market power on US consumers. Agribusiness, 17(1): 59-79.

Sorrentino A., Russo C, Cacchiarelli L., 2016. Food value chain in the EU - How to improve it and strengthen the bargaining power of farmers. In: Research for agri committee - Structural change in EU farming: How can the CAP support a 21st century European model of agriculture? European Parliament, COMAGRI.

Sueyoshi T., Hasebe T., Ito F., Sakai J. and Ozawa W., 1998. DEA-bilateral performance comparison: an application to Japan agricultural co-operatives (Nokyo). Omega, 26(2): 233-248.

Van Herck K., 2014. Assessing efficiencies generated by agricultural Producer Organisations. Report for the EU DG Competition, available at http:// bookshop.europa.eu/it/assessing-efficiencies-generated-by-agricultural-producer-organisations-pbKD0214739/. 